\title{
Gravity induced flow to characterize rheological properties of printable cement-based materials
}

\author{
Yohan Jacquet ${ }^{1}$, Vincent Picandet ${ }^{1}$, Damien Rangeard ${ }^{2}$, Arnaud Perrot ${ }^{1 *}$ \\ ${ }^{1}$ University of South Britany, UMR CNRS 6027, IRDL, 56100 Lorient, France \\ ${ }^{2}$ INSA Rennes, EA 3913, LGCGM, 35000 Rennes, France
}

Received: 30 October 2020 / Accepted: 01 December 2020 / Published online: 29 December 2020

(C) The Author(s) 2020. This article is published with open access and licensed under a Creative Commons Attribution 4.0 International License.

\begin{abstract}
This paper presents testing methods based on the deformation and fracture of fresh cementitious materials subjected only to their own weight. These new methods are dedicated to the study of cementitious materials designed for 3D concrete printing in order to verify rheological requirements related to the process. The first testing method consists of measuring the tip deflection of fresh cementitious materials, horizontally extruded, enabling the determination of the apparent elastic modulus of the material. The second test consists of measuring the tensile strength of material filament leaving the nozzle of a vertical downward extruder. The results of both methods are based on the video capture of the deformation of the materials loaded by gravity, and provide results that are in agreement with tests performed with conventional testing machines (tensile and unconfined compression tests). This work demonstrates the potential of video capture of the gravity induced deformation of cementitious materials to describe the behavior of cementitious materials in the fresh state or for the in-line control of the 3D concrete printing process.
\end{abstract}

Keywords: Rheology; Bending test; Tensile behavior; Elastic modulus; 3D printing

\section{Introduction}

The development of 3D concrete printing (3DCP) is changing the way the rheology of cementitious materials in the fresh state is studied [1-5]. When dealing with conventional casting methods, only the shear flow of the materials is considered, while 3DCP involves new material requirements, such as elastic properties to prevent in-print structure buckling [6], compressive strength to avoid plastic collapse of the base layer [7], and also the tensile strength for the prevention of the initiation of cracks at the surface of the materials [8]. Therefore, tests and protocols need to be developed in order to enable accurate and simple determinations of these fresh state mechanical properties [8-11].

Using gravity in order to assess the rheological behavior of cementitious materials is not a new idea. The Abrams cone, which is the conventional test to control the workability of concrete onsite, is based on the free flow of a cementitious material under its own weight when the cone is lifted and is used in almost all national standards concerning concrete control.

Furthermore, it is possible to link the Abrams cone test results to rheological parameters. Roussel and Coussot have developed a theorical framework that computes the shear yield stress of the materials in a shear flow regime based on the measurement of the spread diameter and it is also used to compute the compressive strength (elongational yield stress) of the materials in a elongational flow regime i.e. for a low slump value [12]. Note that the geometry of the cone can be adapted in order to target a specific rheological parameter [13] and that more sophisticated modeling strategies have been developed for a flow regime combining shear and elongational flows [14].

More recently, video capture has been combined with the Abrams cone slump flow to develop a numerical tool able to turn the slump flow into an accurate rheometer for selfcompacting materials $[15,16]$. This initiative has demonstrated the potential of video capture in order to study the fresh-state behavior of cementitious materials.

The basic aim of this paper is to combine video capture with deformation measurements of the materials under gravity in order to estimate the rheological parameters of cementitious materials required in the design or the in-line control of the 3DCP process.

Two test configurations have been developed in this paper. The first one deals with the measurement of the tip deflection of horizontal extrudates of cementitious materials which is compared with the Timoshenko cantilevered beam theory $[17,18]$. This test enables the estimation of the apparent elastic modulus of the cementitious materials from the tip deformation of the material before material breakage. The second test is a self-tensile test. The breakage of a downward

\footnotetext{
* Corresponding author: Arnaud Perrot, Email: arnaud.perrot@univ-ubs.fr
} 
vertically extruded filament, stretched under its own weight is observed to assess its tensile strength. This test is very similar to the slug test proposed by Ducoulombier et al. [10].

It is important to note that both methods can be easily performed before a 3DCP process by just changing the orientation of the printhead.

Results of these gravity driven tests are satisfactorily compared with results obtained with tensile and compressive tests carried out on a loading machine. This comparison demonstrates the ability of these tests to accurately provide values of useful parameters in a 3DCP process.

\section{Materials}

Both materials used in this study are based on the same mix design, wherein OPC CEMI $52.5 \mathrm{~N}$ (34\% by dry mass) is mixed with standard sand according to EN196-1 (55\% by dry mass) and limestone filler ( $11 \%$ by dry mass). Materials are mixed using tap water at $20^{\circ} \mathrm{C}$ at an effective water to cement ratio of 0.37 and 0.39 respectively. The studied mortars contain a High Range Water Reducing Admixture (HRWRA) at a dosage of $0.15 \%$ compared to the dry mass of cement. Furthermore, in a 3DCP context, the effect of a viscosity modifying agent (VMA) which consists of cellulose ether (DOW Walocel MKX15000 with a viscosity grade from 14000 to 18 $000 \mathrm{mPa} . \mathrm{s})$ is used at a water to VMA mass ratio of $1.25 \%$. According to the crucial role of elastic properties in the collapse of structures during printing [2,6], a decision was made to compare mix designs by considering a similar elastic modulus. Based on squeeze flow tests performed on different samples as proposed in the work of Panda et al. [19], the water to cement mass ratio of mortars displaying the same apparent elastic modulus can be determined. In agreement with these preliminary compressive tests, the amount of water for mix designs containing VMA is increased to reach an adjusted effective water to cement mass ratio increased by $3 \%$ (e.g. $\mathrm{W} / \mathrm{C}=0.37$ becomes 0.40 and $\mathrm{W} / \mathrm{C}=0.39$ becomes $0.42)$.

\section{Elastoplastic properties assessment using a cantilevered beam analogy}

\subsection{Compressive behavior assessment using the squeeze flow test}

Whether adapting the water content of a mix design to reach the same elastic modulus when adding cellulosic ether, or to assess the mechanical behavior of a specific mix design in the fresh state for a 3DCP application, the elastic behavior of the material has to be determined. For this purpose, squeeze flow tests were performed on each material used in this study, at a low compressive rate of $0.5 \mathrm{~mm} . \mathrm{s}^{-1}$ which limits the viscous effect and is sufficient to prevent phase separation [20,21]. In addition, due to the presence of sand grains and the major granular friction phenomena, adopting a slenderness of 2:1 is essential to avoid material consolidation. A $50 \mathrm{~mm}$ diameter sample was set between two lubricated plates, then the squeeze flow test was carried out and analyzed using the assumption of interface slippage [22].
The compressive strength and the mean value of the apparent elastic modulus can thus be determined. Both materials exhibit different pseudo elastic moduli: whereas for the firmest mortar (e.g. for $\mathrm{W}_{\text {eff }} / \mathrm{C}=0.37$ or 0.40 with $\mathrm{CE}$ ) the modulus is measured at $110 \mathrm{kPa}(+/-5 \mathrm{kPa})$, the more fluid ones (e.g. for $\mathrm{W}_{\text {eff }} / \mathrm{C}=0.39$ or 0.42 with $\mathrm{CE}$ ) give a value of $39 \mathrm{kPa}(+/-1 \mathrm{kPa})$. These values will be used as references for the apparent elastic modulus for the four tested materials.

\subsection{Cantilevered beam test}

The cantilevered beam test consists of an analysis of the bending of a horizontally extruded mortar specimen, which is modeled using a cantilevered beam analogy. Sample bending, induced by gravity increases as the material extrusion progresses and the beam length extends. In order to measure the apparent elastic modulus, the study of the bending deformation is carried out at a low level strain rate, until the assumption of the linear elastic behavior becomes invalid (Figure 1). The studied extrudates have a circular cross section with a diameter $D=35.5 \mathrm{~mm}$. This cylindrical geometry avoids geometrical singularities along the specimen surface.

It is important to note that the real reversible linear elastic domain of cementitious material is very limited to a range of strain of less than $1 \cdot 10^{-4}[23,24]$. Here, the measured deflection is also due to additional nonlinear strains and an apparent elastic modulus describing the material deformation before its plastic yielding is identified. Nevertheless, this apparent elasticity occurring before yielding is worth noting in the context of 3DCP since it describes the material's apparent behavior during the process.

The characterization method is based on tracking and plotting the tip deflection $d$ during the extrusion process. From the video recording, the specimen deflection can thus be plotted according to the beam free length. To ensure the accuracy of the elastic measurements of the material, the image resolution has to be sufficient: a full frame camera body equipped with a f/2.8 $25 \mathrm{~mm}$ lens was used and positioned at a distance of $10 \mathrm{~cm}$. Sample scoring was performed every 5 to $25 \mathrm{~ms}$ (depending on extrusion rate) using PyMecaVideo software. Two extrudates velocities of 2 and $9 \mathrm{~mm} / \mathrm{s}$ were tested in this work.

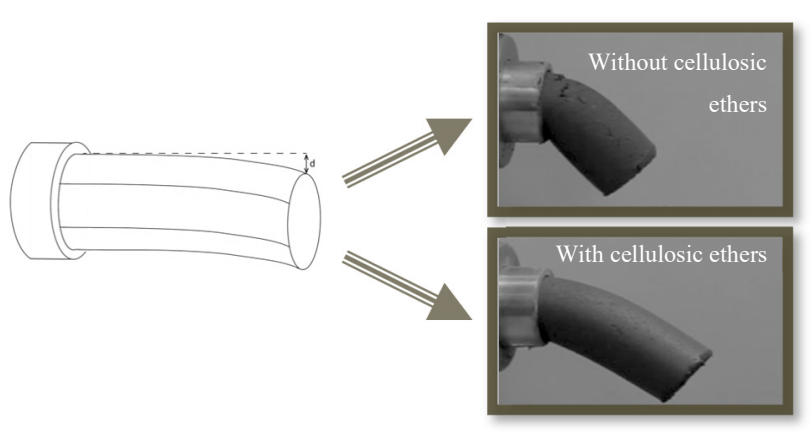

Figure 1. Examples of pictures extracted from the video recording used for the measurement of the tip deflection of the beam $d$.

The correlation between the tip deflection according to the beam free length and the analytical solution provided by 
Timoshenko is performed in order to compute the apparent elastic modulus $E$, that provides the best fit between experiments and modeling. This value is obtained from the beginning of the deflection curve where the material behaves elastically. The Timoshenko beam theory estimates the tip deflection of a cantilevered beam under self-weight bending and considers an elastic material behavior. The shear modulus, material density $\rho$, and geometric features follow Equation 1 . Bending behavior is mainly governed by the free length $\delta L$ of the sample.

$$
d=\frac{2 \rho g \delta L^{4}}{E D^{2}}+\frac{5 \rho g \delta L^{2}}{9 G}
$$

This equation takes into account the circular cross section, $S$, of the extruded sample producing the value of the second moment of section area $I=\frac{\pi D^{4}}{64}$ and reduced cross section $S_{R}=0.9 \cdot S$. The determination of the shear modulus $G$, is made according to the compressive elastic modulus $E$, assuming a Poisson's ratio $v$ equal to 0.4 as proposed by [6] with $G=E / 2(1+v)$.
Figures 2 and 3 illustrate the comparison between measured tip deflections and the Timoshenko model using $E$ values that best fit the beginning of the deflection curve for mortars without cellulosic ether (CE) and with CE respectively. As expected, the model fits efficiently with the experimental curve until a certain threshold value, beyond which the Timoshenko beam theory becomes invalid as the elastic strain limit is exceeded. After this threshold value, the tip deflection suddenly increases because of the occurrence of plastic flow or cracks initation (as ovserved in Figure 1). Table 1 also shows that the apparent modulus $E$ computed from the Timoshenko model fit is very close to the value obtained from compressive tests independently of the extrusion rate. The elastic region can then be considered to assess the correlation between the Timoshenko theory and digital scoring using least-square fit. It exhibits a good agreement in the viscoelastic domain and diverges when plastic deformations (or cracks) occur.

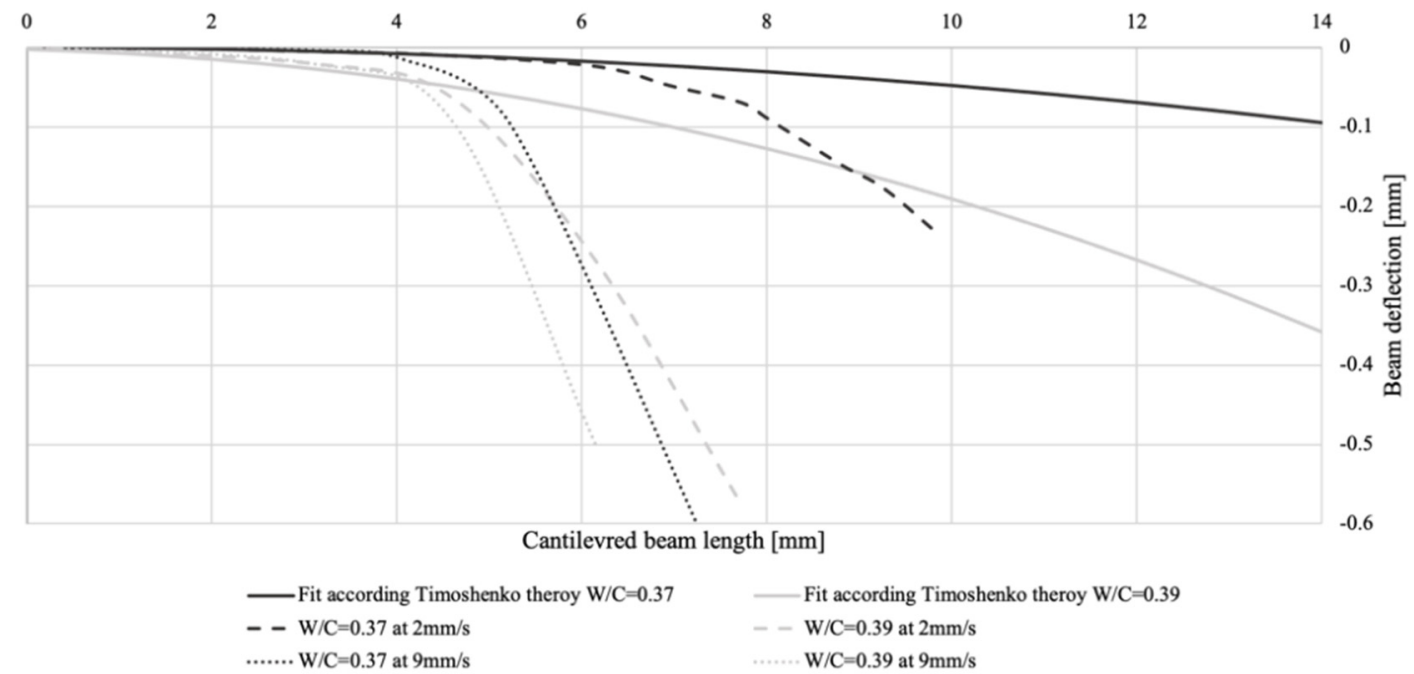

Figure 2. Tip deflection versus extuded specimen length. Comparison between experimental results and the Timoshenko beam theory for a material without CE

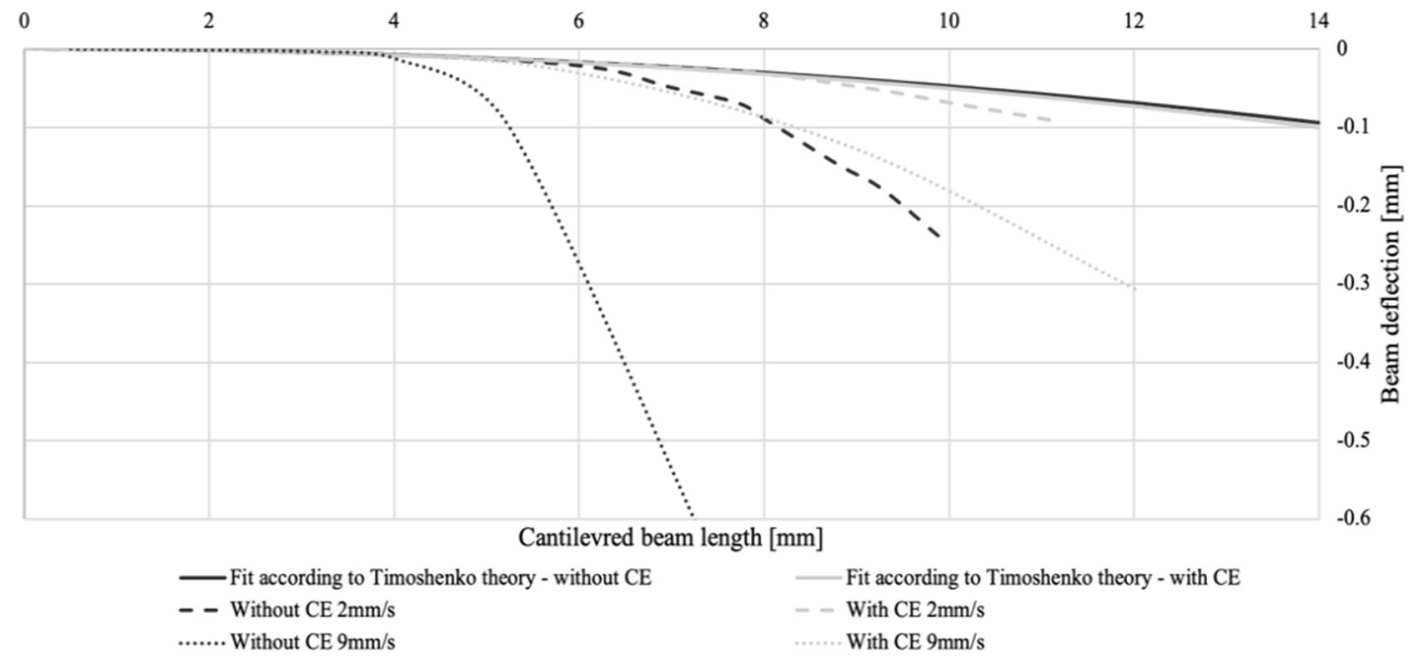

Figure 3. Tip deflection versus extruded specimen length. Comparison between experimental results and the Timoshenko beam theory for a material with CE. 
A second investigation was performed by varying the extrusion rate to determine the influence of material viscosity. For both materials (i.e. with and without CE), a curve transition between solid elastic and viscoplastic fluid behaviors can be observed when the experimental deflection exceeds the prediction given by the elastic Timoshenko modeling. Concentrating on the effect of the extrusion rate on the threshold value (in terms of beam length) in excess of which plastic deformation occurs, it is interesting to note that this threshold value decreases with the extrusion rate. In pratice, this result can be interesting in order to limit cracks and the plastic flow of the material during the deposition step using lower extrusion rates. This study mainly aims to highlight the ability of VMAs to increase the material viscoelastic domain, with further consideration given to its influence on the tensile behavior [25]: a deeper analysis of the impact of VMAs could be performed in further studies.

In consideration of the usually high extrusion rate required for a fast and efficient 3DCP process, it is necessary to control and extend this visco-elastic domain. This could be achieved using cellulosic ethers VMA [26]. As shown in Table 1, and in comparison to Figures 2 and 3 , the addition of VMA helps to extend the viscoelastic domain, as the specimen length before plastic flow is increased.

Table 1. Summary of measured apparent elastic moduli

\begin{tabular}{|l|l|l|l|l|}
\cline { 2 - 5 } \multicolumn{1}{c|}{} & \multicolumn{2}{l|}{ Without CE } & \multicolumn{2}{l|}{ With CE } \\
\hline Extrusion rate & $2 \mathrm{~mm} / \mathrm{s}$ & $9 \mathrm{~mm} / \mathrm{s}$ & $2 \mathrm{~mm} / \mathrm{s}$ & $9 \mathrm{~mm} / \mathrm{s}$ \\
\hline $\begin{array}{l}\text { Beam's free length } \\
\text { at the end of the } \\
\text { assumed elastic } \\
\text { domain [mm] }\end{array}$ & 5.2 & 3.8 & 7.9 & 4.5 \\
\hline $\begin{array}{l}\text { E value used in the } \\
\text { Timoshenko beam } \\
\text { model [kPa] }\end{array}$ & 116 & 105 & \multicolumn{2}{|c|}{} \\
\hline $\begin{array}{l}\text { Efitt elastic modulus } \\
\text { computed by linear } \\
\text { correlation [kPa] }\end{array}$ & 111.7 & 126.1 & 107.24 & 103.65 \\
\hline
\end{tabular}

With regards to the high deflection value (beyond the elastic domain); although a high elastic modulus increases the ability of the material to reach a higher bending strength, plastic collapse induced by plastic flow is still predominating. Flow or fracture can occur and mechanisms have thus to be understood to predict the mode of failure. It is important to note that for a cantilevered extruded specimen, failure is a combination of shear, compression and tension loadings, which can be complex to model, and that the ductility or brittleness of the material in the plastic domain has still to be studied. Nevertheless, cracks appear in many cases on the top of the extrudates (as shown on the top picture of Figure 1) which is the part of the sample that is the most in tension. Therefore, it seems that tensile behavior is governing the initiation of the sample failure.

Even if compressive failure is a very topical issue because of the assessment of the self-weight carrying requirement, the tensile behavior is much less established at this time and requires the further development of experimental tools that will enable its full characterization. This is the aim of the second test developed which is presented in Section 4 of this paper.

\section{Tensile failure behavior \\ 4.1 Gravity driven tensile test}

In accordance with the purpose of this present study, a method is presented in order to characterize the material's tensile strength using a flow-controlled vertically oriented extrusion-based process. A ram extrusion device consisting of a $20 \mathrm{~cm}$ long and $5 \mathrm{~cm}$ in diameter stainless steel cylindrical tank, filled with cementitious material and fitted with a piston and interchangeable cylindrical nozzle is used in this test. Then, the device is fitted on a $45 \mathrm{~cm}$ high steel frame and installed on a tensile-compressive testing machine equipped with a $10 \mathrm{kN}$ load cell. The instantaneous applied force on the piston and the corresponding displacement can be recorded. The extruded sample is shaped by the nozzle cross section which consists of a circular hole with a $14 \mathrm{~mm}$ diameter located at the bottom of the extrusion device (Figure 4).
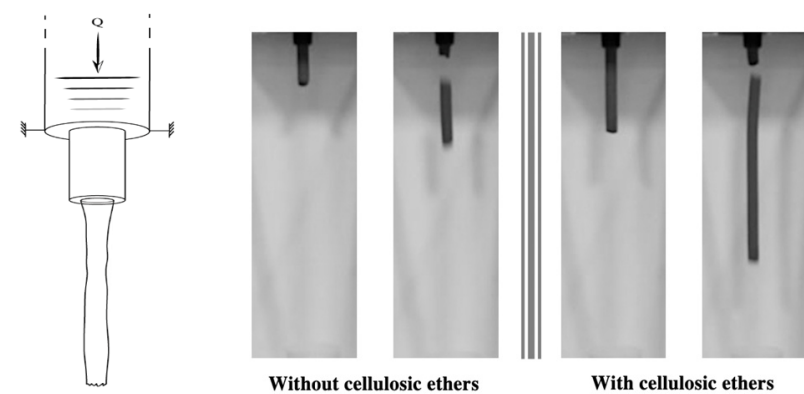

Figure 4. Schematic view of the self-traction tests on extrudate samples and pictures captured during the experiments.

A decision was made to impose a low piston velocity of $25 \mathrm{~mm} / \mathrm{min}$ in order to perform the test in quasi-static conditions. This velocity must however be sufficient enough to avoid the occurrence of the material consolidation process [27]. The piston velocity $V_{\text {piston }}$ is computed from the displacement, imposed by the compression machine, which computes the theoretical sample displacement velocity at the extruder nozzle $V_{\text {sample }}$ according to the following Equation 2 , based on the theory of mass conservation of an incompressible material:

$$
V_{\text {sample }}=V_{\text {piston }} \frac{D^{2}{ }_{\text {piston }}}{D^{2}{ }_{\text {nozzle }}}
$$

The experimental procedure of this study is able to provide the material tensile strength using two different strategies. The first one consists of the determination of the ultimate tensile stress $\sigma_{\text {tens,GD }}$ by weighting the broken fallen samples while the second one consists of the determination of the ultimate tensile stress using real-time monitoring of the sample, based on the video capture of the test (Figure 5). Following the same method as for the cantilevered sample test [Part 3.2], the sample is scored every $50 \mathrm{~ms}$ using PyMecaVideo software. 

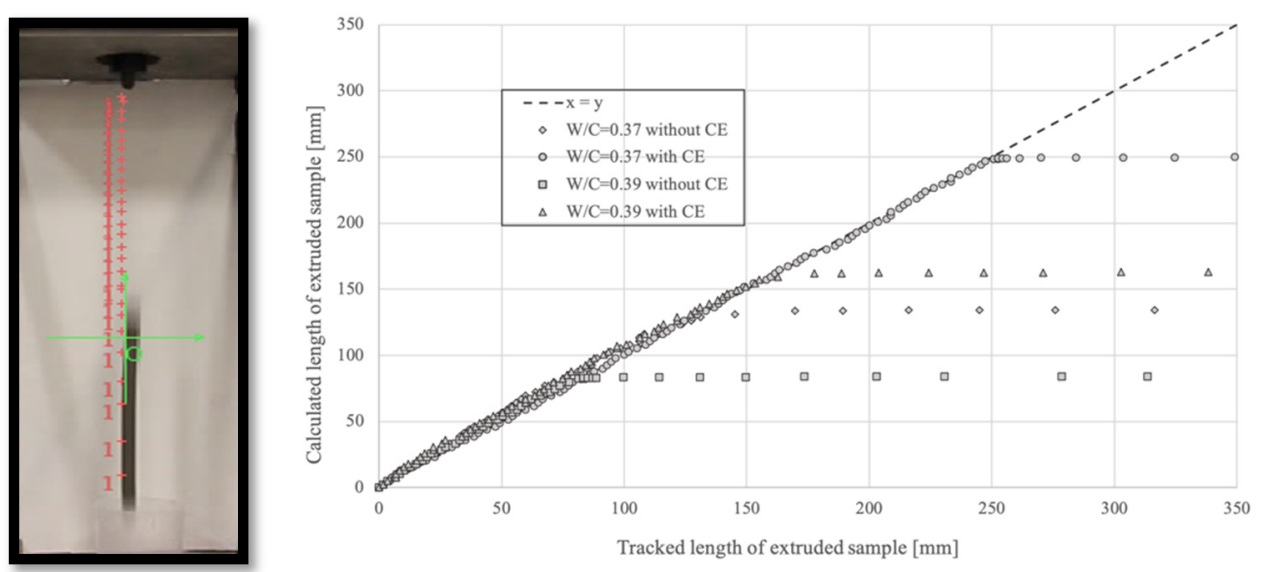

Figure 5. Comparison of the theoretical length of the unbroken specimen with the tracked position of the bottom end of the extrudates. The divergence between theory and measurement signifies the sample breakage.

Table 2. Masses of the material leading to extrudates fracture, obtained by the weighting of the fallen samples, and by video tracking from which the corresponding tensile strength of the material is computed. Tests are carried out at a piston velocity of $25 \mathrm{~mm} / \mathrm{min}$ (omitting viscous effects).

\begin{tabular}{|c|c|c|c|c|c|c|}
\hline & & $\rho$ & $m_{\text {weigthed }}$ & $\begin{array}{l}m_{\text {computed }} \\
\text { from video } \\
\text { tracking }\end{array}$ & Deviation & $\begin{array}{l}\sigma_{\text {tens, } G D}, \\
\text { from video } \\
\text { tracking }\end{array}$ \\
\hline & & {$\left[\mathrm{kg} / \mathrm{m}^{3}\right]$} & [g] & [g] & [g] & {$[\mathrm{kPa}]$} \\
\hline \multirow{2}{*}{$W / C=0.37$} & Without CE & 2250 & 29.53 & 28.06 & 3.41 & 1.82 \\
\hline & With CE & 2071 & 61.74 & 61.52 & 0.51 & 4.00 \\
\hline \multirow{2}{*}{$W / C=0.39$} & Without CE & 2246 & 17.92 & 18.32 & 3.96 & 1.19 \\
\hline & With CE & 2090 & 53.20 & 53.73 & 0.81 & 3.49 \\
\hline
\end{tabular}

Ultimate tensile stresses can be determined from Equation 3 using relevant material and geometrical properties (i.e. sample diameter, density), when the measured position of the bottom end of the extrudate diverges from the theoretical position, indicating that the extrudate has been broken under its own weight:

$$
\sigma_{\text {tens,GD }}=\frac{m g}{\pi R^{2}}=\rho g L_{\text {sample }}
$$

where $m$ is the mass of the extrudate, $R$ its radius and $L_{\text {sample }}$ its length. Based on sample weighting and on digital scoring, the gravity driven self-tension test determines the tensile strength of cement-based materials, which can thus be compared by a statistical analysis of the results deviation. This deviation is computed taking into account the respective strength values of both methods ( 5 repetitions of the test for the weighting method, and 3 repetitions of the GD tracking method). The deviation value given in Table 3 corresponds to the deviation between mean strength values of the weighting and tracking methods. Note that the use of cellulosic ethers significantly improves tensile strength and reproducibility. For instance, the tensile strength is doubled for the mix with a $\mathrm{W} / \mathrm{C}$ ratio equal to 0.37 and tripled for a $\mathrm{W} / \mathrm{C}$ ratio equal to 0.39 , as shown in Table 2.

\subsection{Comparison with controlled tensile test using the Double Dumbbell Device tensile test}

In order to validate the tensile strength measured using vertical extrusion self-traction tests, a tensile test device was developed (Figure 6a): the Double Dumbbell Device - 3DTT consists of two dumbbell shaped tanks independently controlled in displacement. The lower part is clamped on a MCR702 Anton Paar rheometer and the upper one is attached to a 50N load cell using a SCF-7 tool. Each dumbbell part has been designed and 3D printed using PETG with a circular cross section having a $25 \mathrm{~mm}$ diameter. The rheometer is here used as a controlled strain rate tensile machine with the data recording of the displacement and the tensile force. The analysis of the data in large deformation plots the tensile stress curves according to the tensile true strain (as shown in Figure 6b). Tensile true strain - also called Hencky strain - is determined according to $\varepsilon_{t, \text { true }}=\ln \left(1+\frac{\Delta H}{H_{0}}\right)$ using an initial sample $H_{0}$ of 14 $\mathrm{mm}$ which corresponds to the height of the cylindrical sample having a constant diameter of $25 \mathrm{~mm}$ and the tensile stress is computed by averaging the recorded tensile tests on the initial sample cross section. 

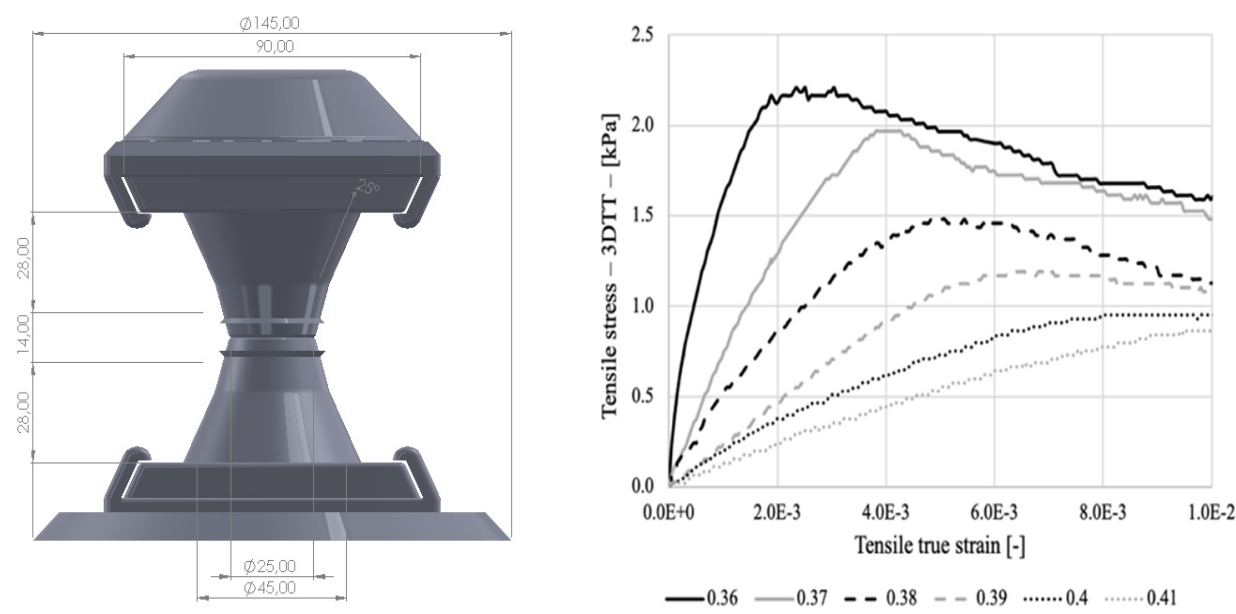

Figure 6. a) Diagram of the 3DTT and b) an example of stress vs. strain curves obtained from data analysis of the test.

Preliminary experiments [25] have shown that a Double Dumbbell Device with these dimensions, can be used with materials having a shear yield stress higher than $0.5 \mathrm{kPa}$ in order to have no material flow from the upper part of the device. It is necessary that the material remains stable in the upper part of the device to avoid an undesired gravity flow during the test for the more fluid materials. The test is performed at a low tensile rate of $100 \mu \mathrm{m} \cdot \mathrm{s}^{-1}$ to satisfy quasistatic test conditions (to omit the viscous effect) similar to gravity driven tests. As a result, respective tensile strengths can thus be compared. Both characterization methods exhibit very close strength values as shown in Table 3, especially regarding the difference of magnitude with compressive ones, $\sigma_{\text {comp }} / \sigma_{\text {tens }}=6.85$ for $\mathrm{W} / \mathrm{C}=0.37$ and $\sigma_{\text {comp }} / \sigma_{\text {tens }}=3.57$ for $\mathrm{W} / \mathrm{C}=0.39$. This type of mortar exhibits a complex asymmetrical behavior between compression and tension just as a self-consolidating concrete after a few hours of hydration when the hydrates form an entangled network with pressure dependent mechanical properties [28].

Table 3. Summary of the tensile strength obtained with 3DTT and gravity driven self-traction tests. Comparison with compressive strength measured using squeeze flow.

\begin{tabular}{|l|l|l|l|}
\cline { 2 - 4 } \multicolumn{1}{c|}{} & $\begin{array}{l}\sigma_{\text {comp, Squeeze }} \\
\text { Flow }\end{array}$ & $\begin{array}{l}\sigma_{\text {tens, Gravity }} \\
\text { Driven }\end{array}$ & $\sigma_{\text {tens, 3DTT }}$ \\
\cline { 2 - 5 } & {$[\mathrm{kPa}]$} & {$[\mathrm{kPa}]$} & {$[\mathrm{kPa}]$} \\
\hline $\mathrm{W} / \mathrm{C}=0.37$ & 12.59 & 1.82 & 1.85 \\
\hline $\mathrm{W} / \mathrm{C}=0.39$ & 4.32 & 1.19 & 1.23 \\
\hline
\end{tabular}

\section{Conclusion}

Inspired from the combination of the slump flow, which is a gravity driven flow, and using video capture in order to obtain a shear flow rheometer, two new tests (called the cantilevered beam test and the gravity driven tensile test) were proposed to measure material parameters that are required in the design, monitoring, and optimization of 3DCP processes. The cantilevered beam test estimates the apparent elastic modulus, while the gravity driven tensile test estimates the tensile strength of the cement-based materials.
Both original methods are based on video capture and image analysis and enable the material parameters to be estimated accurately. Results obtained with the new developed tests are in agreement with values measured using more a conventional device such as compressive and tensile tests using a controlled strain rate loading machine. The apparent elastic modulus obtained with the cantilevered beam tests is similar to the one obtained using compression tests on samples with an aspect ratio of 2 . In addition, the tensile strengths obtained with the gravity driven tests are the same as those obtained with the tensile tests carried out with the loading machine (using the 3DTT device).

These promising results demonstrate the ability of video capture to be used as efficiently in on-site mechanical tests in the context of the 3DCP as for an in-line monitoring of the process.

The tests are used here in quasi-static conditions within the framework of this study to compute material parameters, but it was also highlighted that some viscous aspects originate additional stresses: a link between the material extrusion rate (directly related to the shear rate) and material behavior during the printing process has to be taken into account in further studies.

Furthermore, from a purely mechanical point of view, this study has highlighted that cementitious materials exhibit a complex rheological behavior: asymmetry of strengths between tensile and compression loads and cracks initiation of plastic flow beyond the elastic domain. These observations lead to the consideration of a combination of different testing procedures in order to fully describe the rheological behavior of cementitious materials in the context of 3DCP in which materials are likely to undergo different combinations of loads at each step of the printing process.

\section{CRediT authorship statement}

Yohan Jacquet: Conceptualization, Methodology, Writing original draft, Investigation, Validation.

Vincent Picandet: Conceptualization, Methodology, Writing review and editing. 
Damien Rangeard: Conceptualization, Methodology, Writing - review and editing.

Arnaud Perrot: Conceptualization, Methodology, Writing original draft, Writing - review and editing, Supervision.

\section{References}

[1] R.J.M. Wolfs, F.P. Bos, T.A.M. Salet, Triaxial compression testing on early age concrete for numerical analysis of 3D concrete printing. Cem Concr Compos (2019) 103344. https://doi.org/10.1016/i.cemconcomp.2019.103344

[2] N. Roussel, Rheological requirements for printable concretes, Cem Concr Res (2018) 112: 76-85. https://doi.org/10.1016/j.cemconres.2018.04.005

[3] L. Reiter, T. Wangler, A. Anton, R.J. Flatt, Setting on demand for digital concrete - Principles, measurements, chemistry, validation. Cem Concr Res (2020) 132: 106047. https://doi.org/10.1016/j.cemconres.2020.106047

[4] N. Roussel, H. Bessaies-Bey, S. Kawashima, D. Marchon, K. Vasilic, R. Wolfs, Recent advances on yield stress and elasticity of fresh cementbased materials. Cem Concr Res (2019) 124:105798. https://doi.org/10.1016/j.cemconres.2019.105798

[5] V. Mechtcherine, F.P. Bos, A. Perrot, W.R.L. da Silva, V.N. Nerella, S. Fataei, R.J.M. Wolfs, M. Sonebi, N. Roussel, Extrusion-based additive manufacturing with cement-based materials - Production steps, processes, and their underlying physics: A review. Cem Concr Res (2020) 132:106037. https://doi.org/10.1016/i.cemconres.2020.106037

[6] R.J.M. Wolfs, F.P. Bos, T.A.M. Salet, Early age mechanical behaviour of $3 \mathrm{D}$ printed concrete: Numerical modelling and experimental testing. Cem Concr Res (2018) 106: 103-116. https://doi.org/10.1016/i.cemconres.2018.02.001

[7] A. Perrot, D. Rangeard, A. Pierre, Structural built-up of cement-based materials used for 3D-printing extrusion techniques, Mater Struct (2016) 49: 1213-1220. https://doi.org/10.1617/s11527-015-0571-0

[8] Y. Jacquet, V. Picandet, D. Rangeard, A. Perrot, Gravity Driven Tests to Assess Mechanical Properties of Printable Cement-Based Materials at Fresh State, in: Second RILEM International Conference on Concrete and Digital Fabrication: Digital Concrete 2020, RILEM Bookseries Vol.28, Springer Nature, Springer, 2020, 280-289. https://doi.org/10.1007/978-3-030-49916-7 29

[9] P. Carneau, R. Mesnil, N. Ducoulombier, N. Roussel, O. Baverel, Characterisation of the Layer Pressing Strategy for Concrete 3D Printing, in: Second RILEM International Conference on Concrete and Digital Fabrication: Digital Concrete 2020, RILEM Bookseries Vol.28, Springer Nature, 2020, 185-195. https://doi.org/10.1007/978-3-030-49916-7_19

[10] N. Ducoulombier, P. Carneau, R. Mesnil, L. Demont, J.-F. Caron, N. Roussel, "The Slug Test": Inline Assessment of Yield Stress for Extrusion-Based Additive Manufacturing, in: Second RILEM International Conference on Concrete and Digital Fabrication: Digital Concrete 2020, RILEM Bookseries Vol.28, Springer Nature, Springer, 2020, 216-224. https://doi.org/10.1007/978-3-030-49916-7 22

[11] A. Kazemian, X. Yuan, E. Cochran, B. Khoshnevis, Cementitious materials for construction-scale 3D printing: Laboratory testing of fresh printing mixture. Constr Build Mater (2017) 145: 639-647. https://doi.org/10.1016/j.conbuildmat.2017.04.015

[12] N. Roussel, P. Coussot, "Fifty-cent rheometer" for yield stress measurements: From slump to spreading flow. J Rheol (2005) 49: 705-718. https://doi.org/10.1122/1.1879041

[13] N. Roussel, C. Stéfani, R. Leroy, From mini-cone test to Abrams cone test: measurement of cement-based materials yield stress using slump tests. Cem Concr Res (2005) 35: 817-822. https://doi.org/10.1016/i.cemconres.2004.07.032

[14] A. Pierre, C. Lanos, P. Estellé, Extension of spread-slump formulae for yield stress evaluation. Appl Rheol (2013) 23:63849. http://doi.org/10.3933/ApplRheol-23-63849

[15] F. Toussaint, eFlow - A Pocket Concrete Rheometer, in: International RILEM Workshop on Rheological Measurements of Cement-Based Materials IRWRMC'18, PRO 132, RILEM Proceedings, 2019, 64-68.

[16] L.N. Thrane, C. Pade, C.V. Nielsen, Determination of rheology of selfconsolidating concrete using the 4C-Rheometer and how to make use of the results, Journal of ASTM International (2009) 7:1-10. https://doi.org/10.1520/JAl102003
[17] S. Timoshenko, D.H. Young, Elements of strength of materials, Van Nostrand Princeton, 1962.

[18] C.E. Augarde, A.J. Deeks, The use of Timoshenko's exact solution for a cantilever beam in adaptive analysis. Finite Elem Anal Des (2008) 44: 595-601. https://doi.org/10.1016/j.finel.2008.01.010

[19] B. Panda, J.H. Lim, M.J. Tan, Mechanical properties and deformation behaviour of early age concrete in the context of digital construction. Compos B: Eng (2019) 165: 563-571. https://doi.org/10.1016/j.compositesb.2019.02.040

[20] Z. Toutou, N. Roussel, C. Lanos, The squeezing test: a tool to identify firm cement-based material's rheological behaviour and evaluate their extrusion ability. Cem Concr Res (2005) 35: 1891-1899. https://doi.org/10.1016/i.cemconres.2004.09.007

[21] A. Perrot, D. Rangeard, N. Venkatesh, V. Mechtcherine, Extrusion of cement-based materials - an overview. RILEM Tech Lett (2019) 3: 9197. https://doi.org/10.21809/rilemtechlett.2018.75

[22] J. Engmann, C. Servais, A.S. Burbidge, Squeeze flow theory and applications to rheometry: a review. J Nonnewton Fluid Mech (2005) 132: 1-27. https://doi.org/10.1016/i.jnnfm.2005.08.007

[23] N. Roussel, A. Lemaître, R.J. Flatt, P. Coussot, Steady state flow of cement suspensions: A micromechanical state of the art. Cem Concr Res (2010) 40: 77-84. https://doi.org/10.1016/j.cemconres.2009.08.026

[24] Y. Qian, S. Kawashima, Flow onset of fresh mortars in rheometers: Contribution of paste deflocculation and sand particle migration. Cem Concr Res (2016) 90: 97-103. https://doi.org/10.1016/j.cemconres.2016.09.006

[25] Y. Jacquet, A. Perrot, V. Picandet, Assessment of asymmetrical rheological behavior of cementitious material for 3D printing application. Cem Concr Res 140 (2021) 106305 https://doi.org/10.1016/j.cemconres.2020.106305

[26] C. Brumaud, R. Baumann, M. Schmitz, M. Radler, N. Roussel, Cellulose ethers and yield stress of cement pastes. Cem Concr Res (2014) 55: 14-21. https://doi.org/10.1016/j.cemconres.2013.06.013

[27] H. Khelifi, A. Perrot, T. Lecompte, D. Rangeard, G. Ausias, Prediction of extrusion load and liquid phase filtration during ram extrusion of high solid volume fraction pastes. Powder Technol (2013) 249: 258268. https://doi.org/10.1016/j.powtec.2013.08.023

[28] L.K. Mettler, F.K. Wittel, R.J. Flatt, H.J. Herrmann, Evolution of strength and failure of SCC during early hydration. Cem Concr Res (2016) 89: 288-296. https://doi.org/10.1016/i.cemconres.2016.09.004 